ered over with something, to prevent the exhalations from the alluvial soil on which the city is built ; either round or paving siones, or bricks, or shells and sand, or asphaltum.

3. That the owners should be compelled by law to fill up all low swampy lots within the limits of the city.

4. That all offal deposited in the streets should be promptly removed; and if possible, before the beat of the day.

5. That whenever the river is high, the water shonld be allowed to run through the streets day and night: and that when it is too low, the water works, or if necessary, additional works established for the purpose, should be brought into play.

6. That above all, particular attention should be paid by the city authorities, to the alluvial bank, particularly under the wharves of the Second Municipality, which is annually uncovered as the river falls, exposing an immense surface of fresh deposit, covered with every kind of decaying vegetable and animal matter, which daily accumulates, either carried there by eddy currents of the river, or thrown in by the inhabitants.

The committee deem this last consideration to be of the bighest importance, as there is every reason to believe that the bank of the river, under the wharves, is more productive of disease in the summer than all other causes in the city, combined.

7. That instead of depositing the filth and offal collected in the streets by the scavengers, in empty lots or in the rear of the city, it is recommended to the city authorities to have all such filth and offal thrown into the current of the river.

They would also observe, that the measures just recommended would not be attended with one-fourth of the expense of a quarantine establishment properly condueted; while, should they be pushed forward with zeal and energy, the time might, and no doubt would, ere long arrive, when New Orleans would no longer be within the yellow fever region; and consequently exempt, not only from that pestilence, but from all the other fatal diseases of the summer and fall, peculiar to our climate and to our position. This accomplished-what would there remain to retard the growth and prosperity of our city? She would speedily accomplish her high destiny, and in less than a quarter of a century become the most wealthy, prosperous and populous eity in the western hemisphere. -Nevo Orleans Med. Jour.

\title{
CASE OF INJURY OF THE HIP, BY A FALL, WITH EXFOLIATION OF THE BONE.
}

By John M. Ross, M.D., of Marion, Mississippi.

THE ease which I propose to detail, if it furnishes nothing new in principle or practice, affords, at least, a striking illustration of the vis medicatrix natura, and of the aid which it is often in our power to render to her curative efforts, by slight surgical interference.

The subject of the injury and operation which I am aboust to describe, 
was a negro man, aged 45 years, of robust frame and good health. Eight years ago he full from the second story of a house, by which he received a severe contusion in the right hip, but no fracture that could be discovered. T!s: parts were lacerated to a considerable extent, as well as bruised. From bad managernent, or because the injury was more serious than was suspected at the time, be did not recover from the wound for near a twelve month. About that time he was able to resume his active occupation, and all that remained of the injury was a dull, dragging pain in the parts that had been wounded, the pain increasing in wet or cloudy weather, as also during any disease. He remained in this condition until Friday, the 13th of March last, when he was suddenly taken with a severe pain in the hip, extending to the lumbar region, accompanied with a severe chill, which was followed by fever. On Saturday the pain extended to the abdomen, and was more severe. The chill and fever also returned. These regular returns continued, with increased pain and soreness, until Tuesday, the 17th, when I was called in great haste to see him.

I found him suffering excruciating pain, and much prostrated; his countenanc3 was haggard, pupils much dilated; a cold, clammy perspiration covered his entire surface. 'The abdomen was remarkably tender on pressure, and he experienced great difficulty in discharging his urine. It was ascertained that large quantities of pus passed from his bowels ; his pulse was about 40 in a minute; he complained of the lower part of his bowels mostly, and said that be could feel something hard there.

From these alarming symptoms, I entered into a close examination, and soon found a spicula of bone lodged in the rectum, so near the external orifice, that I could get hold of it with a common pair of forceps ; it was, however, apparently fast and immovable, being held by its rough, serrated edges.

Having the patient in a convenient posture, I made further examination with a probe, and soon found that the bone had not yet passed into the rectum, but was just entering. In size the bone was about one inch and a half in length, and three quarters of an inch in width, with an irregular, rough appearance. Finding that it could not be removed without an operation, I made an incision by a scalpel, having introduced a grooved director through the anus, and along the superior margin of the bone to its full extent. The cut extended about three quarters of an inch, and the bone was extracted with a pair of forceps. But little hemorrhage ensued, nor was the quantity of pus discharged as great as I had expected. The operation was completed by bringing the edges of the wound together and applying simple dressings. Afterwards I gave the patient twenty drops of laudanum, and thirty drops of tincture of catechu, and ordered that he should abstain from all highly-seasoned or stimulating food and drinks. His pulse soon rose to about 70, and he fell into a tranquil sleep, in which state he remained until the following morning. The next day after the operation, I returned and found him in a state of perfect ease. I ordered him to take two ounces of castor oil, and permitted him to drink a small quantity of soup; directed that he be kept 
in a perfect state of rest, in a recumbent posture. Returned next day, and found my patient quite cheerful, without any discharge of pus, bowels open, skin moist, tongue clean, no appearance of inflammation, divided parts healing well, pulse about 75. I again ordered oil to keep the bowels soluble, and put the patient upon a low diet. I saw him again on the 20th; everything was progressing well; no pain or fever. The same directions to be continued. My visits were now discontinued, and I saw him no more until a few days since, when he had regained his strength, felt his hip stronger than it had been before for eight years, and with less pain in it ; in a word, as he expressed it himself, feeling like a new man.-West. Jour. Med. and Surg.

\section{CASE. OF IN'TUSSUSCEPTION.}

Dr. S. J. Jeaffreson related the following case at a late meeting of the Royal Medical and Chirurgical Society.

The case was that of a young man, aged 17, to whom the author was called on the 26th of May, 1844. He was laboring under general febrile symptoms; there was an anxious expression of countenance; the abdomen not tender under pressure, but becoming tympanitic; nothing could be retained on the stomach ; the matters vonited had a grass-green appearance; there was painful tenesmus without evacuations. Calomel and opium, purgatives of senna, croton oil, \&c., with turpentine glysters, were used up to the 28 th, without success. On that day, the author considered that decided symptons of inflammation of the bowels and peritoneum bad set in; the belly was generally tender, especially in the left hypochondrium, where a distinct hard tumefaction was observed; leeches, fornentations, \&c., were used in addition to the other means, but no evacuations took place until the 31 st, when there were very copious and offensive discharges from the bowels, and the vomiting ceased. From this date, the patient gradually recovered, copious evacuations took place, charged with much gelatinous-looking mucus, and, on one occasion, a small quantity of blood.

On the Sth of June there was discharged from the bowels what the author supposed to be either a portion of the small intestine, or a cast of it (of coagulable lymph). It was about two inches and a half or three inches in length, and of a tubular form, smelt horribly putrid, and one or two minute points presented the appearance of sphacelus. After this, with some slight interruption, the patient recovered. The substance voided was examined under the microscope by Mr. Toynbee, who stated that he found cellular tissue, traces of bloodvessels, and nerves and epithelium.

Mr. Dalrymple, who also examined it, thought that involuntary muscular fibre might also be detected, but could not speak positively from the preparation having been placed in spirits of wine for some time.

The author draws attention to one point in the treatment-namely, the abstinence from any active depletion on the 28th, when symptoms of 